\title{
Bioavailability Studies on Developed Prochlorperazine Maleate Sustained Release Tablets by HPLC
}

\author{
Dhandapani Nagasamy Venkatesh ${ }^{1 *}$, Sundaram Sankar ${ }^{2}$, Subramania Nainar Meyyanathan ${ }^{3}$, \\ Selvadurai Muralidharan ${ }^{3}$, Ramaswamy Shanmugam ${ }^{3}$, Kannan Elango ${ }^{4}$, \\ Bhojraj Suresh ${ }^{5}$ and Kumaraswamy Santhi ${ }^{6}$
}

\author{
${ }^{1}$ Department of Pharmaceutics, Ooty, Tamil Nadu, India \\ ${ }^{2}$ Department of Pharmaceutical Chemistry, Ooty, Tamil Nadu, India \\ ${ }^{3}$ Department of Pharmaceutical Analysis, Ooty, Tamil Nadu, India \\ ${ }^{4}$ Principal, J.S.S.College of Pharmacy, Ooty, Tamil Nadu, India \\ ${ }^{5}$ Vice-Chancellor, JSS University, Mysore, India \\ ${ }^{6}$ Department of Pharmaceutics, Grace College of Pharmacy, Palakkad, Kerala, India
}

\begin{abstract}
A sensitive and reproducible high performance liquid chromatography (HPLC) method has been developed and validated for the quantification of prochlorperazine sustained release tablets in human plasma, after solid phase extraction (SPE). Best chromatographic resolution was achieved on a reverse-phase Phenomenex $\mathrm{C}_{18}$ column using the mobile phase consisted of a mixture of $20 \mathrm{mM}$ disodium hydrogen ortho phosphate-acetonitrile (95:5) in an isocratic elution with a total run time of $12 \mathrm{~min}$. Linear plot was obtained in the concentration range of 15-300 $\mathrm{ng} / \mathrm{ml}\left(r^{2}=0.99\right)$. Lower limit of quantification (LLOQ) was found to be $15 \mathrm{ng} / \mathrm{ml}$. Average recovery of the analyte was found to range from 98.25 to $99.13 \%$ in plasma at the concentrations of 45,150 and $270 \mathrm{ng} / \mathrm{ml}$. The intra and inter-day relative standard deviations of low quality control (LQC), medium quality control (MQC) and high quality control (HQC) of prochlorperazine were found to be $2.63,3.25,2.83$ and $3.57,5.88$ and 3.78 respectively. The present method was successfully applied in the pharmacokinetic study of prochlorperazine in human plasma.
\end{abstract}

Keywords: Prochlorperazine maleate; Sustained release; HPLC; Validation; Bioavailability studies

\section{Introduction}

Prochlorperazine maleate [2-chloro-10-[3-(4-methyl-1piperazinyl) propyl]-10H-phenothiazine (Z)-2-butenedioate $(1: 2)]$ is a phenothiazine derivative used as an anti-emetic. It has a prominent antiemetic activity and is most often used for the (short-time) treatment of nausea, vomiting and vertigo. A recent research about emergency department treatment of migraine headache indicated that prochlorperazine was statistically superior to octreotide in clinical success rate and pain relief in migraine patients (Miller et al., 2009). Only few methods have been reported by HPLC and LC-MS (Yan et al., 2009; Mou et al., 1997; El-Yazigi et al., 1995: Fowler et al., 1986). The present developed HPLC method is relatively simple, rapid and highly sensitive $(6 \mathrm{ng} / \mathrm{ml})$ in the determination of prochlorperazine sustained release tablets in human plasma after solid phase extraction (SPE) and has been successfully applied in the human pharmacokinetic study. No SR formulation of prochlorperazine is available in India and we developed SR tablets of prochlorperazine and quantification in human plasma.

\section{Experimental}

\section{Chemicals and reagents}

Reference standards of prochlorperzine Maleate (purity: 99.67\%) and acyclovir (internal standard, IS 99.01\%) were procured from M/s. Nicholas Piramal (Mumbai, India) and Matrix Laboratories (Hyderabad, India) respectively. HPLC grade acetonitrile was procured from E.Merck (Mumbai, India) and other chemicals used were of analytical grade. Purified water from a Milli-Q-system (Millipore, Bangalore, India) was used throughout the analysis.

\section{Human}

Human studies were approved by human ethical committee, JSS College of Pharmacy, Ooty, India.

\section{Instrumentation}

A Shimadzu LC 2010AHT HPLC with an online vacuum deaerator, a constant temperature automatic sampler, class VP data station was used for data processing.

\section{Chromatographic conditions}

Liquid chromatographic separations were achieved using a Phenomenex $5 \mu \mathrm{C}_{18}$ column $(250 \mathrm{~mm} \times 4.6 \mathrm{~mm})$. The column and auto sampler tray temperature were kept constant at $40^{\circ} \mathrm{C}$ and $4^{\circ} \mathrm{C}$, respectively. The mobile phase consist of a mixture of 20 $\mathrm{mM}$ disodium hydrogen ortho phosphate-acetonitrile (95:5) and was delivered at a flow-rate of $0.7 \mathrm{ml} / \mathrm{min}$. The sample injection volume was $100 \mu$ l.

\section{Development of prochlorperazine maleate sustained release (SR) tablets}

Prochlorperazine maleate SR tablets were prepared by the wet granulation method. All the composition, with the exception of *Corresponding author: Dhandapani Nagasamy Venkatesh,
Department of Pharmaceutics, J.S.S.College of Pharmacy, Ootacamund-
643001, Tamilnadu, India, E-mail: nagasamyvenkatesh@rediffmail.com

Received December 01, 2009; Accepted December 28, 2009; Published December 28, 2009

Citation: Venkatesh DN, Sankar S, Meyyanathan SN, Muralidharan S, Shanmugam R,et al. (2009) Bioavailability Studies on Developed ProchlorperazineMaleate Sustained Release Tablets by HPLC. J Bioanal Biomed 1: 054-057. doi:10.4172/1948-593X.1000012

Copyright: () 2009 Venkatesh DN. This is an open-access article distributed under the terms of the Creative Commons Attribution License, which permits unrestricted use, distribution, and reproduction in any medium, provided the original author and source are credited. 
magnesium stearate and talc were thoroughly mixed in a tumbling mixer for $5 \mathrm{~min}$ and wetted in a mortar with isopropyl alcohol. The wet mass was sieved (16 mesh) and granules were dried at $60^{\circ} \mathrm{C}$ for $2 \mathrm{~h}$. The dried granules were sieved ( $\left.22 \mathrm{mesh}\right)$ and these granules were lubricated with a mixture of magnesium stearate and talc $(2: 1)$. The prochlorperazine maleate tablets were prepared using an electrically operated punching machine. Compression was performed after granulation process with a single punch press applying a compression force of a $9 \mathrm{KN}$ (preliminary work) or $12 \mathrm{KN}$ (experimental design), equipped with a 8 $\mathrm{mm}$ concave punch. For the preliminary work, batches of 100 tablets were prepared. Each batch of experimental design consisted of 100 tablets (drug content in the tablet was $15 \mathrm{mg}$ ).

\section{Preparation of stock solution and sample solutions}

Stock solution of prochlorperazine maleate was prepared by dissolving the accurately weighed reference compound in water and acetonitrile (1:1) to give a final concentration of $1 \mathrm{mg} / \mathrm{ml}$, stored at $4^{\circ} \mathrm{C}$ until it is used. The solution was then serially diluted with water and mixed with blank human plasma to achieve standard working solutions at concentration of 15.0, 30.0, 45.0, $60.0,120.0,180.0,240.0$ and $300.0 \mathrm{ng} / \mathrm{ml}$ for prochlorperazine, respectively. A $50 \mu \mathrm{g} / \mathrm{ml}$ internal standard working solution was prepared by diluting the $1 \mathrm{mg} / \mathrm{ml}$ stock solution of internal standard with millipore water.

\section{Sample preparation}

A $0.5 \mathrm{ml}$ aliquot of human plasma sample was mixed with 0.5 $\mathrm{ml}$ of internal standard working solution $(100 \mu \mathrm{g} / \mathrm{ml}$ of acyclovir $)$ were added and mixed. The resulting solution was vortexed and extracted solid phase extraction (SPE). The drug was extracted using $0.5 \mathrm{ml}$ of the mobile phase and analysed.

\section{Assay validation \\ Sensitivity and specificity}

The lower limit of quantification was determined as the minimum concentration that could be accurately and precisely quantified (lowest data point of the standard curve). The specificity of the assay for the analytes versus endogenous substances in the matrix was assessed comparing the lowest concentration in the calibration curves with reconstitutions prepared with drugfree plasma from five different humans. Limit of detection was found to be $6 \mathrm{ng} / \mathrm{ml}$ and limit of quantification was $15 \mathrm{ng} / \mathrm{ml}$.

\section{Accuracy and precision}

The accuracy and precision (presented as relative standard deviation, R.S.D.) of the assay were determined using quality control (QC) samples at 45,150 and $270 \mathrm{ng} / \mathrm{ml}$. Accuracy (\%) was determined by the percentage ratio of measured over spiked QC concentration (mean of measured/ spiked $\times 100 \%$ ). Intra-day precision was determined by analyzing replicate aliquots of QCs $(n=5$ per each concentration) on the same day. Inter-day precision was determined by repetitive analysis of QC samples (each concentration) on five consecutive days.

\section{Recovery and ionization}

To investigate the recovery of prochlorperazine by the solid phase extraction (SPE) method, plasma samples were spiked with prochlorperazine at concentrations of 45,150 and $270 \mathrm{ng} / \mathrm{ml}$. The resulting peak-area ratios (analyte: internal standard) were J Bioanal Biomed compared with that of the standards prepared in mobile phase to provide the recovery values. The absolute peak areas of control plasma extracted and then spiked with a known amount of drug, to neat standards injected directly in the same reconstituted solvent.

\section{Stability}

To evaluate sample stability after three freeze-thaw cycles and at room temperature, five replicates of QC samples at each of the low, medium and high concentrations were subjected to three freeze-thaw cycles or were stored at room temperature for $4 \mathrm{~h}$ before sample processing, respectively. Five replicates of QC samples at each of the low and high concentrations were processed and stored under autosampler conditions for $24 \mathrm{~h}$. Stability was assessed by comparing the mean concentration of the stored QC samples with the mean concentration of freshly prepared QC samples.

\section{Clinical design}

The study protocol was approved by the Institution Review Board. Twelve healthy male Indian subjects with mean age group $20-25$ years and average weight $65.8 \pm 6.1 \mathrm{~kg}$ were included in the study. Subjects were excluded from the study if one or more of following criteria were present at time of medical screening: allergic to prochlorperazine, history or clinical data of renal or liver disease, positive test for hepatitis B, HIV, history of alcohol, drug addiction or donated blood within 72 days prior to study. Test $(15 \mathrm{mg})$ and reference $(5 \mathrm{mg})$ formulations were administered with $240 \mathrm{ml}$ of water. The study was conducted in a single dose, open and complete design.

Volunteers were fasted overnight before and $4 \mathrm{~h}$ after drug administration. Blood sample $(5 \mathrm{ml})$ were collected at $0.0,0.5$, $1.0,1.5,2.0,2.5,3.0,4.0,6.0,8.0,12.0$ and $24.0 \mathrm{~h}$ of post drug administration through an indwelling cannula into heparinised glass vials. After drug administration standard breakfast and lunch were provided at 4 and $6 \mathrm{~h}$ post dose. The blood samples were immediately centrifuged, plasma was separated and stored at $20^{\circ} \mathrm{C}$ until analysed. The plasma samples obtained at various time intervals were analysed by the developed HPLC method.

\section{Application of the assay}

The developed HPLC assay method was used in the pharmacokinetic study after oral administration of prochlorperazine to human volunteers. Volunteers were fasted for $12 \mathrm{~h}$ before dosing and $4 \mathrm{~h}$ afterwards, with free access to water. The samples were collected in pre-labeled vacutainers containing sodium citrate as an anti-coagulant and centrifuged at $4000 \mathrm{rpm}$ for 10 min at $15^{\circ} \mathrm{C}$ and plasma was collected in pre-labeled sample collection tube. A wash out period of 7 days was observed between the two phases of the study. The samples were stored in the deep freezer at $-70 \pm 5^{\circ} \mathrm{C}$ until analyzed by a validated HPLC method.

\section{Results and Discussion}

\section{Method development}

Prochlorperazine is a water insoluble drug. Hence, an attempt has been made to extract the drug from plasma by precipitating the plasma samples with solvents like acetonitrile, perchloric acid and methanol. It was found that the analyte recovery was Volume 1(1) : 054-057 (2009) - 055 


\section{Journal of Bioanalysis \& Biomedicine - Open Access}

JBABM/Vol.1 Issue 1

less with these precipitating agents, may be due to decrease in the solubility of prochlorperazine in water after the addition of these solvents. The solid phase extraction showed good recovery with no interference.

\section{Validation}

\section{Specificity}

No additional peaks due to endogenous substances that could have interfered with the detection of the compounds of interest were observed. Representative chromatograms for blank plasma (Figure 1), prochlorperazine and acyclovir in volunteers sample are presented in (Figure 2).

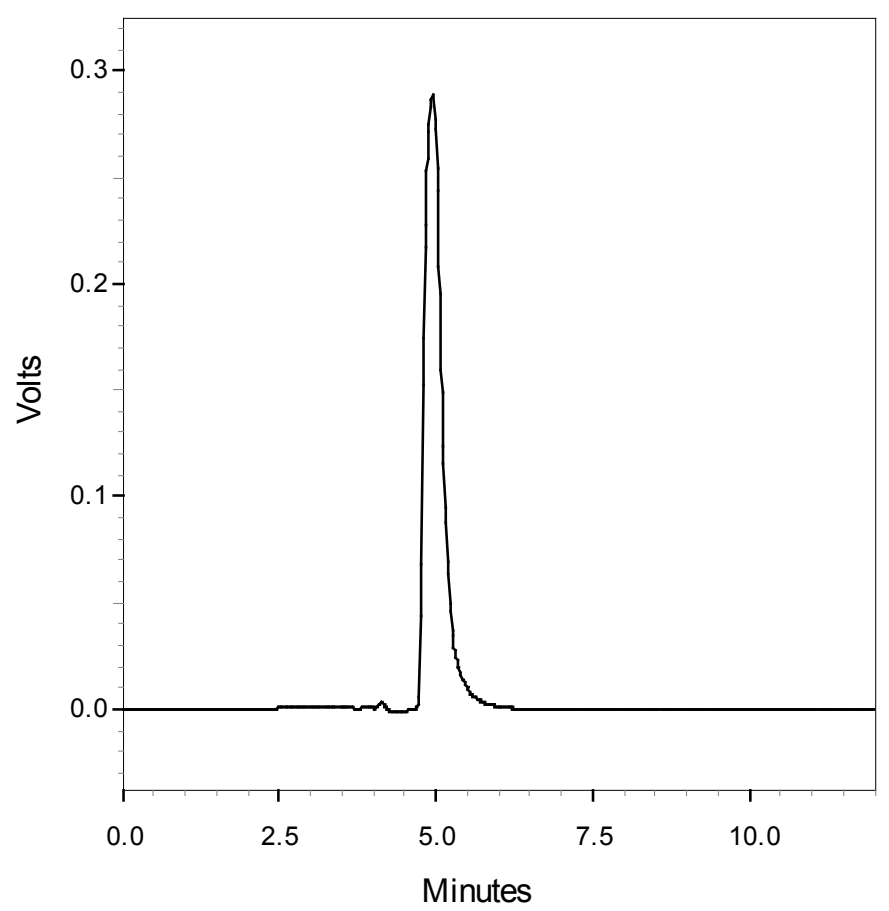

Figure 1: Blank chromatogram of human plasma.

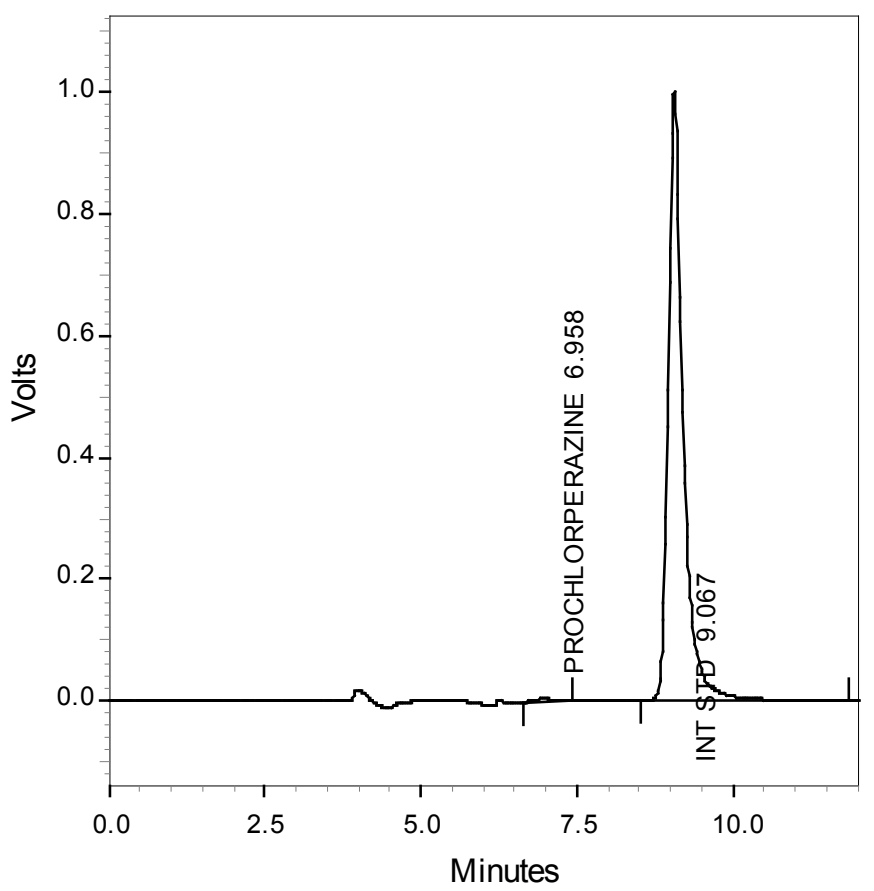

Figure 2: Typical chromatogram of Prochlorperazine with internal standard in human plasma at 4 hour.

\section{Linearity and lower limit of quantification}

The linear regression analysis of prochlorperazine was constructed by plotting the peak-area ratio of prochlorperazine to the internal standard $(y)$ versus analyte concentration $(\mu \mathrm{g} / \mathrm{ml})$ in spiked plasma samples $(x)$. The average regression equation of these curves and their correlation coefficients $(r)$ were calculated as follows: $\left(r^{2}=0.998, n=8\right)$, weighting coefficient: $1 / x$; it showed good linear relationship between the peak areas and the concentrations. The lower limit of quantitation, defined as the lowest concentration analyzed with accuracy within $\pm 15 \%$ and a precision $\pm 15 \%$, was $6 \mathrm{ng} / \mathrm{ml}$ for determination of prochlorperazine in plasma. The limit has already been sufficient for pharmacokinetic studies of prochlorperazine.

\section{Precision}

The intra-day precision (presented as relative standard deviation) is shown in Table 1. The inter-day precision was studied over 5 days, and the results were also given in Table 1 .

\section{Recovery and stability}

The absolute recoveries of prochlorperazine at concentrations of 45, 150 and $270 \mathrm{ng} / \mathrm{ml}(n=5)$ were $99.05,97.98$ and $99.10 \%$, respectively. Stability of prochlorperazine during sample handling (freeze-thaw and short-term temperature) and the stability of processed samples were evaluated and prochlorperazine was stable for at least $4 \mathrm{~h}$ at room temperature in plasma samples, for $24 \mathrm{~h}$ in autosampler conditions and in plasma samples following three freeze-thaw cycles.

\section{Pharmacokinetic study}

The assay was conducted to obtain pharmacokinetic data for prochlorperazine in human plasma after oral administration (15.0 $\mathrm{mg}$ ) application of the HPLC method developed here to in vivo pharmacokinetic studies in humans. The area under the plasma concentration (AUCs curve) of prochlorperazine after oral ad-

\begin{tabular}{|l|c|c|c|}
\hline \multicolumn{4}{|c|}{ Intra day $(\mathrm{n}=5)$} \\
\hline $\begin{array}{l}\text { Nominal } \\
\text { concentration } \\
(\mathrm{ng} / \mathrm{ml})\end{array}$ & 45 & 150 & 270 \\
\hline Mean \pm S.D & $45.054 \pm 2.638$ & $149.040 \pm 0.18$ & $270.423 \pm 2.836$ \\
Accuracy (\%) & 99.88 & 100.64 & 99.84 \\
R.S.D (\%) & 0.13 & 0.04 & 0.03 \\
\hline \multicolumn{4}{|c|}{ Inter day (n=5) } \\
\hline Nominal & \multicolumn{3}{|c|}{} \\
Concentration & 1 & 3 & 5 \\
$($ ng/ml) & \multicolumn{4}{|c|}{} & & \\
\hline Mean \pm S.D & $0.98 \pm 0.11$ & $2.93 \pm 0.11$ & $4.77 \pm 0.34$ \\
\hline Accuracy (\%) & 101.76 & 102.12 & 104.60 \\
\hline R.S.D (\%) & 0.11 & 0.04 & 0.07 \\
\hline
\end{tabular}

Table 1: Precision of prochlorperazine in human plasma.

\begin{tabular}{|c|c|c|}
\hline $\begin{array}{c}\text { Pharmacokinetic } \\
\text { parameters }\end{array}$ & Developed SR Product & Reference \\
\hline $\mathrm{AUC}_{0-\mathrm{t}}(\mathrm{ng} . \mathrm{h} / \mathrm{ml})$ & 27442.62 & 1615.123 \\
\hline $\mathrm{AUC}_{0-\infty}(\mathrm{ng} . \mathrm{h} / \mathrm{ml})$ & 23450.25 & 1894.857 \\
\hline $\mathrm{C}_{\max }(\mathrm{ng} . / \mathrm{ml})$ & 297.8904 & 218.4162 \\
\hline $\mathrm{t}_{\max }(\mathrm{h})$ & 5 & 3.83 \\
\hline $\mathrm{k}_{\mathrm{eli}}\left(\mathrm{h}^{-1}\right)$ & 0.11209 & 0.178829 \\
\hline $\mathrm{t}_{1 / 2}(\mathrm{~h})$ & 6.1970 & 3.89381 \\
\hline
\end{tabular}

Table 2: Pharmacokinetic parameters after oral dose of $5 \mathrm{mg}$ (reference) and developed SR tablets $(15 \mathrm{mg})$ prochlorperazine maleate administration to humans.

Volume 1(1) : 054-057 (2009) - 056 
Citation: Venkatesh DN, Sankar S, Meyyanathan SN, Muralidharan S, Shanmugam R,et al. (2009) Bioavailability Studies on Developed ProchlorperazineMaleate Sustained Release Tablets by HPLC. J Bioanal Biomed 1: 054-057. doi:10.4172/1948-593X.1000012

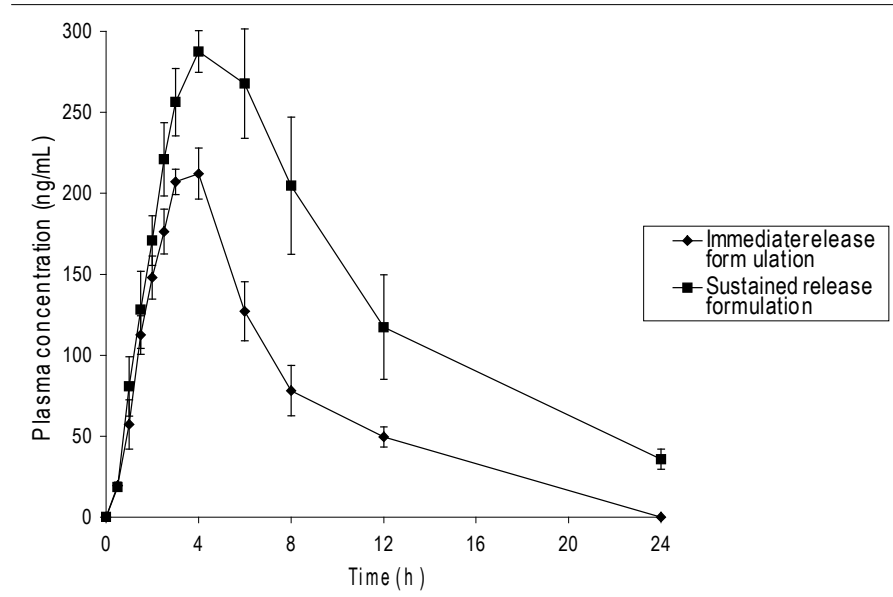

Figure 3: Mean plasma concentrations (ng/ml) for prochlorperazine maleate immediate release and sustained release product.

ministrations was 27442.62 and $1615.123 \mu \mathrm{g} \mathrm{h} / \mathrm{ml}$, respectively. The mean $C_{\max }$ value was 297.89 and $218.41 \mathrm{ng} / \mathrm{ml}$ corresponding mean $t_{\max }$ value was 5 and $3.83 \mathrm{~h}$. The mean plasma elimination half-life was 6.19 and $3.89 \mathrm{~h}$. for test and reference respectively, other pharmacokinetic parameters in this study are shown in Table 2 and Figure 3. The present method could be applied to pharmacokinetic studies of lower dose administration of prochlorperazine.

\section{Conclusion}

SPE of prochlorperazine from plasma was found to be more precise than the liquid-liquid extraction. The current method guarantees a high precision, accuracy, recovery and a relatively short analysis time and will be a useful tool in the pharmacokinetic study of prochlorperazine in humans.

\section{References}

1. El-Yazigi A, Abdel Wahab F, Afrane B (1995) Stability study and content uniformity of prochlorperazine in pharmaceutical preparations by liquid chromatography. J Chromatogr A 690: 71-76. » CrossRef » PubMed » Google Scholar

2. FDA Guidance for Industry (2001) Bioanalytical Method Validation, US Department of Health and Human Services, Food and Drug Administration, Centre for Drug Evaluation and Research (CDER), Center for Veterinary Medicine (CVM). » CrossRef » PubMed » Google Scholar

3. Fowler A, Taylor W, Bateman DN (1986) Plasma prochlorperazine assay by high-performance liquid chromatography - electrochemistry. J Chromatogr 380: 202-205. » CrossRef » PubMed » Google Scholar

4. Miller MA, Levsky ME, Enslow W, Rosin A (2009) Randomized evaluation of octreotide vs prochlorperazine for ED treatment of migraine headache. Am J Emerg Med 27: 160-164. » CrossRef » PubMed » Google Scholar

5. Mou C, Ganju N, Sridhar KS, Krishan A (1997) Simultaneous quantitation of plasma doxorubicin and prochlorperazine content by high-performance liquid chromatography. J Chromatogr B Biomed Sci Appl 703: 217-224.» CrossRef » PubMed » Google Scholar

6. Yan M, Zhu YG, Li HD, Chen BM, Ma N, et al. (2009) Quantification of prochlorperazine maleate in human plasma by liquid chromatography-mass spectrometry: Application to a bioequivalence study. J Chromatogr B 877: 3243-3247. » CrossRef » PubMed » Google Scholar 